\title{
Learning-Dependent Synaptic Modifications in the Cerebellar Cortex of the Adult Rat Persist for at Least Four Weeks
}

\author{
Jeffrey A. Kleim, ${ }^{1,4}$ Kapil Vij, ${ }^{4}$ David H. Ballard, ${ }^{4}$ and William T. Greenough ${ }^{1,2,3,4}$ \\ Departments of ${ }^{1}$ Psychology and ${ }^{2} \mathrm{Cell}$ and Structural Biology, and ${ }^{3}$ Neuroscience Program, and ${ }^{4}$ Beckman Institute, \\ University of Illinois, Urbana, Illinois 61801
}

\begin{abstract}
Several experiments have demonstrated increased synapse number within the cerebellar cortex in association with motor skill learning but not with motor activity alone. The persistence of these synaptic changes in the absence of continued training was examined in the present experiment. Adult female rats were randomly allocated to either an acrobatic condition (AC) or a motor activity condition (MC). The AC animals were trained to traverse a complex series of obstacles, and each $\mathrm{AC}$ animal was pair-matched with an $\mathrm{MC}$ animal that traversed an obstacle-free runway. These animals were further assigned to one of three training conditions. Animals in the EARLY condition were trained for 10 consecutive days before being killed, animals in the DELAY condition received the same $10 \mathrm{~d}$ of training followed by a $28 \mathrm{~d}$ period without training, and animals
\end{abstract}

in the CONTINUOUS condition were trained for the entire $38 \mathrm{~d}$. Unbiased stereological techniques were used to obtain estimates of the number of synapses per Purkinje cell within the cerebellar paramedian lobule. Results showed the AC animals to have significantly more synapses per Purkinje cell than the $\mathrm{MC}$ animals in all three training conditions. There were no differences in the number of synapses per Purkinje cell among the EARLY, DELAY, and CONTINUOUS conditions. These data demonstrate that both the motor skills and the increases in synapse number presumed to support them persist in the absence of continued training.

Key words: motor learning; synaptogenesis; persistence; cerebellum; synaptic plasticity; rat
Experience can alter neuronal morphology in a manner that may support memory formation (Greenough and Bailey, 1988; Bailey and Kandel, 1993). A pattern of structural changes resulting from learning has emerged from studies of differential rearing conditions and formal training. Rodents reared in complex housing conditions have thicker visual cortices (Diamond et al., 1964), neurons with more dendritic material (Volkmar and Greenough, 1972; Globus et al., 1973), and increased cortical synapse/neuron ratios (Turner and Greenough, 1983; Bhide and Bedi, 1984; Turner and Greenough, 1985). Similar changes have also been observed after various different behavioral manipulations, including maze training (Greenough et al., 1979; Chang and Greenough, 1982), sensitization (Bailey and Chen, 1983), and motor skill learning (Greenough et al., 1985; Withers and Greenough, 1989; Black et al., 1990; Kleim et al., 1994).

If memory is represented in the brain through modifications in neuronal structure, then these changes should persist for as long as the encoded experience. The persistence of some of the anatomical changes described above has been examined in reversal experiments in which animals are reared in a complex environment followed by a period of time in standard labora-

Received July 11, 1996; revised Oct. 21, 1996; accepted Oct. 24, 1996.

This work was supported by National Institute on Aging Grants AG10154 and MH40631, National Institute of Mental Health Grant MH35321, The Kiwanis Foundation, the Retirement Research Foundation, and a Natural Sciences and Engineering Research Council of Canada fellowship. We thank Amity Carrubba, Jennifer Drew, and Jennifer Kelly for assistance in training the animals and printing the micrographs, the Beckman Institute Optical Visualization Facility for use of their stereology system, and the University of Illinois Center for Electron Microscopy for the use of their facilities.

Correspondence should be addressed to William T. Greenough, Beckman Institute, University of Illinois, 405 North Mathews Avenue, Urbana, IL 61801.

Copyright (C) 1997 Society for Neuroscience 0270-6474/97/170717-05\$05.00/0 tory cages. These studies have shown that the increased cortical weight (Katz and Davies, 1984) and dendritic arborization (Camel et al., 1986) observed in rats reared in a complex environment tend to persist. Some of the behavioral consequences of complex housing, such as improved performance on a Hebb-Williams maze, may also persist (Forgays and Read, 1962). A direct examination of how termination versus continued training affects the experience-dependent anatomical and behavioral adaptations within the same experiment has not been conducted.

Motor learning paradigms provide the opportunity to examine more specifically the development of a set of behaviors in relation to the anatomical changes presumed to support them. The cerebellum has been shown to be involved in motor skill learning: a number of studies have demonstrated impairments in motor learning and sensory-motor associations after cerebellar lesions (Lincoln et al., 1982; Hore and Vilis, 1984; Lavond et al., 1990; Thompson et al., 1990) as well as alterations in cerebellar physiology in association with learning (Gilbert and Thach, 1977; Berthier and Moore, 1986; Ojakangas and Ebner, 1992; Bendre et al., 1995). Recent work has also shown that animals trained on a complex motor learning task had increased numbers of synapses per Purkinje cell within the cerebellar cortex (Black et al., 1990; Federmeier et al., 1994; Kleim et al., 1994) in comparison to both active and inactive controls. Together these data indicate that the cerebellum plays a role in motor learning and that changes in Purkinje cell morphology may underlie skill acquisition/retention. These results also provide the opportunity to examine how the learning-dependent anatomical and behavioral changes are affected by removal from continued training. Here we examine the persistence of the increased synapse number and the acquired 
motor skills observed after a brief period of training on a complex motor learning task.

\section{MATERIALS AND METHODS}

Behavioral training. Forty-eight 3- to 4-month-old female, Long-Evans, hooded rats were randomly allocated to either an acrobatic condition (AC) or a motor activity condition (MC). Animals in the $\mathrm{AC}$ group were trained to traverse an elevated obstacle course consisting of ropes, ladders, chains, and parallel bars requiring substantial motor coordination to complete. The time to traverse each obstacle on each trial was recorded. Although errors were not recorded in this experiment, previous experiments using similar training procedures have demonstrated progressive decreases in the number of errors/trial (see Table 1). Each AC animal was pair-matched with an MC animal that was forced to traverse a flat, obstacle-free runway equal in length to the $\mathrm{AC}$ task. If the $\mathrm{AC}$ animals stopped at any point during a task, they were immediately given a gentle prod to the hindquarters by the experimenter. When an $\mathrm{AC}$ animal received a prod, an experimenter would also simultaneously prod the paired MC animal such that both animals spent equal amounts of time on their respective training apparati and received comparable amounts of handling. In a previous study, Black et al. (1990) found that extensive physical activity in running wheels or on a treadmill had no effect on synaptic numbers, so the MC group was adopted in this experiment to assess the effects of handling. Animals from both groups were then further assigned to one of three training conditions. In the EARLY condition (AC, $n=8$; MC, $n=8$ ), rats were trained for 10 consecutive days before being killed, whereas animals in the DELAY condition (AC, $n=8$; MC, $n=8$ ) received the same $10 \mathrm{~d}$ of training followed by a $28 \mathrm{~d}$ period without training. On the last day of the delay period, the animals were given two trials on the task so that any effects of the delay on task performance could be examined. Finally, animals in the CONTINUOUS condition (AC, $n=8$; MC, $n=8$ ) were trained for the entire $38 \mathrm{~d}$ before being killed. All animals were killed within 15 min of their last training session.

Tissue preparation. After training, the animals were anesthetized with pentobarbital $(100 \mathrm{mg} / \mathrm{kg})$ and transcardially perfused with $2 \%$ paraformaldehyde $/ 2.5 \%$ glutaraldehyde in $0.1 \mathrm{M}$ phosphate buffer, $\mathrm{pH} 7.4$, and post-fixed overnight at $4^{\circ} \mathrm{C}$. Approximately 10 sagittal $(300 \mu \mathrm{m})$ sections were taken through one hemisphere of the paramedian lobule (PML) using a vibratome. The sections of PML were then washed in cacodylate buffer $(0.1 \mathrm{M})$, post-fixed in $2 \%$ osmium tetroxide $/ 1.5 \%$ potassium ferrocyanate in $0.1 \mathrm{M}$ cacodylate buffer for $2 \mathrm{hr}$, and stained en block with $2 \%$ uranyl acetate for $45 \mathrm{~min}$. The sections were then gradually dehydrated in alcohol, transferred into propylene oxide, and embedded in Medcast resin. All tissue samples were then coded with respect to experimental condition before data analysis. One animal had to be removed from the anatomical analysis because of inadequate tissue perfusion.

\section{Stereological methods}

The number of synapses per Purkinje cell within the PML was estimated using quantitative stereological methods. Previous experiments have shown that experience can lead to an increase in the volume of neuropil (Rosenzweig et al., 1962; Turner and Greenough, 1985; Black et al., 1990). Because of this volume increase, measures of synapse density alone may not accurately reflect changes in synapse number. In conditions of stable neuron number, however, estimates of synapses per neuron accurately reflect changes in synapse number (Anker and Cragg, 1974). By obtaining the density of neurons and the density of synapses per unit volume, the number of synapses per neuron can be calculated and used to measure changes in synapse number (Turner and Greenough, 1983; Black et al., 1990).

\section{Purkinje cell density}

Eighty serial $1 \mu \mathrm{m}$ sections were taken through one block of PML from each animal using a diamond histo-knife (Diatome) and an ultramicrotome. These sections were mounted on chrom alum gelatin-coated slides and stained with Toluidine blue. With use of a computer-assisted microscope and a locally written stereology software package (Phokus on Stereology), the physical disector (Sterio, 1984) was used to obtain measures of Purkinje cell density. This method involves comparing two serial sections, the Reference section and the Lookup section. Within an unbiased counting frame of a known area, the number of nucleoli (each Purkinje cell having only one) that are present in the Reference section

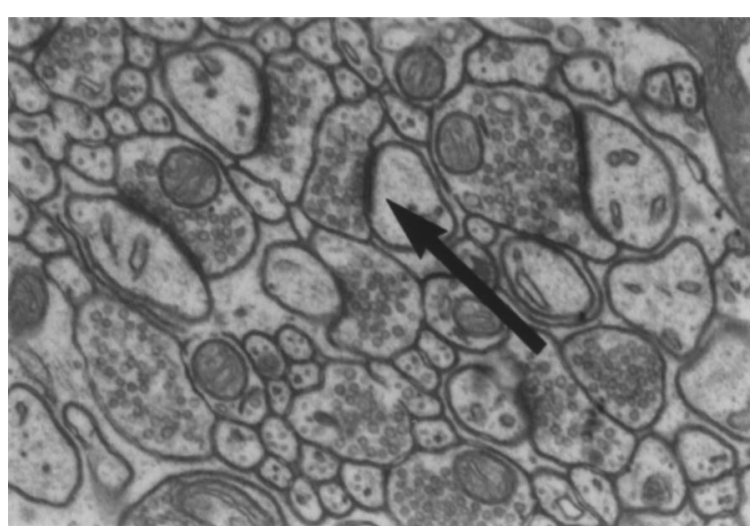

Figure 1. An electron micrograph showing a typical synapse (arrow) within the molecular layer of the PML $(18,000 \times$ magnification $)$.

but not the Lookup section $\left(Q^{-}\right)$are counted. The disector volume of tissue through which the cells are counted $\left(V_{\text {dis }}\right)$ is given by:

$$
V_{\text {dis }}=\left(A_{\text {frame }}\right)(H)
$$

where $A_{\text {frame }}$ is the area of the counting frame and $H$ is the section thickness multiplied by the number of sections. The neuronal density $\left(N v_{\text {Pcell }}\right)$ is then determined by:

$$
N v_{\text {Pcell }}=\frac{Q^{-}}{V_{\text {dis }}}
$$

This method allows for an accurate estimation of Purkinje cell density (Black et al., 1990), which is unbiased with respect to cell size and shape (Sterio, 1984; Pakkenberg and Gundersen, 1988).

\section{Synapse density}

After the $1 \mu \mathrm{m}$ sectioning, a small pyramid was trimmed into the molecular layer of the cerebellar cortex using a $1 \mu \mathrm{m}$ Toluidine blue-stained section from that block as a guide. From the pyramid, 20 silver/gray serial sections ( $\sim 70 \mathrm{~nm}$ thick) were taken using a diamond knife (Diatome) and an ultramicrotome (Reichert Ultracut S). Sections were collected on Formvar-coated, slotted copper grids and stained with lead citrate. One micrograph $(22,000 \times$ print magnification) was taken from the same position in each section using a JEOL $100 \mathrm{C}$ electron microscope. Synapses were identified by the presence of a postsynaptic density and at least three vesicles in the presynaptic element (Fig. 1). The physical disector method was again used to determine synapse density where the number of synapses present in the Reference section but not the Lookup section were counted $\left(Q^{-}\right)$through a known volume of tissue $\left(V_{\mathrm{dis}}\right)$. The number of synapses per Purkinje cell was then obtained by dividing the density of synapses per cubic millimeter by the density of neurons per cubic millimeter. Section thickness was assumed to be $1 \mu \mathrm{m}$ for the calculation of Purkinje cell density and $70 \mathrm{~nm}$ for the calculation of synapse density. Although it is likely that subtle variations in section thickness occur, this variation was assumed to occur nonsystematically across treatment conditions. As such, it would merely increase variance somewhat, making treatment effects more difficult to detect.

\section{RESULTS}

\section{Behavioral}

A split-plot ANOVA with DAY of training as a within-subject factor revealed a significant effect of DAY on the mean time/trial/ task for AC animals in the EARLY $\left(F_{(7,72)}=14.24 ; p<0.001\right)$, $\operatorname{DELAY}\left(F_{(7,80)}=23.31 ; p<0.001\right)$, and CONTINUOUS $\left(F_{(7,296)}=32.54 ; p<0.001\right)$ conditions with the mean time/trial/ task significantly decreasing as training progressed (Fig. 2). Previous experiments have shown that this decrease in time reflects a progressive decrease in the number of foot faults (errors) committed by the animals on each task (Table 1). Other behavioral changes observed in the AC animals included a tendency to move on to the next task without hesitation as well as a reduction in the 


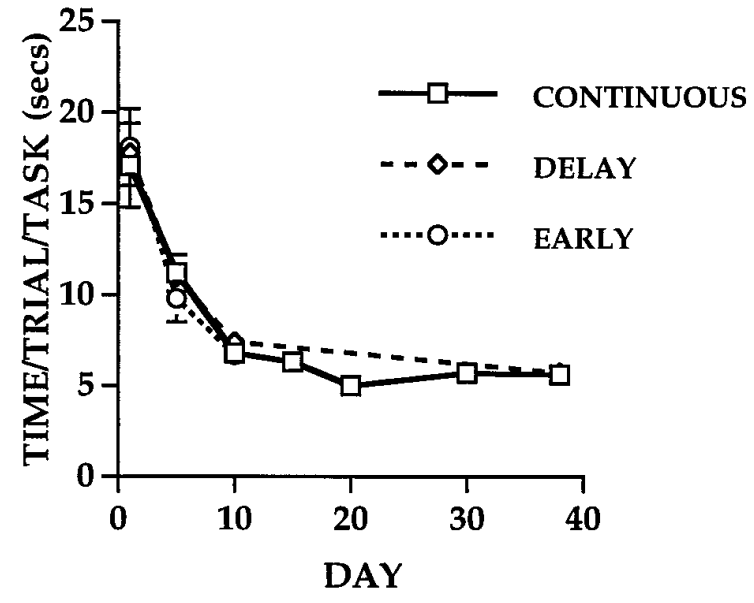

Figure 2. Performance of animals in all three conditions on the acrobatic task ( \pm SEM). The mean time/trial/task significantly decreased in all three conditions as training progressed (see text).

\begin{tabular}{llll}
\hline \multicolumn{2}{l}{ Table 1. Mean number of errors/task/trial } \\
Experiment & Day 1 & Day 15 & Day 30 \\
\hline Kleim et al., 1994 & $0.95 \pm(0.58)$ & $0.36 \pm(0.21)$ & $0.21 \pm(0.11)$ \\
Federmeier et al., 1994 & $1.12 \pm(0.73)$ & $0.28 \pm(0.13)$ & $0.10 \pm(0.04)$ \\
Kleim et al., 1996b & $1.96 \pm(0.85)$ & $0.18 \pm(0.06)$ & N.A.
\end{tabular}

Summary of data from three previous experiments showing the mean number of errors/task/trial $( \pm$ SEM). In each experiment the number of errors can be seen to decrease progressively with training. It should be noted that slightly different training protocols were used in these three experiments. In the Kleim et al. (1994) and Federmeier et al. (1994) experiments, the animals were trained for $30 \mathrm{~d}$ with five trials per day, whereas in the Kleim et al. (1996b) study, two trials per day were given for $15 \mathrm{~d}$, which possibly explains the discrepancy in the initial error rates.

number of prods during the performance of each task. In the present experiment, the DELAY animals had a mean time/trial/ task comparable to that of the CONTINUOUS animals despite the $28 \mathrm{~d}$ period without training, indicating that the skills of these animals persisted in the absence of continued training.

\section{Anatomical}

A two-way ANOVA with CONDITION and GROUP as betweensubject factors revealed a significant main effect of GROUP on the number of synapses per Purkinje cell $\left(F_{(1,41)}=21.48 ; p<\right.$ $0.01)$. Subsequent multiple comparisons (Student Neuman-Keuls, $p<0.05)$ revealed that the AC animals had significantly more synapses per Purkinje cell than the MC animals in the EARLY (Fig. 3A), DELAY (Fig. 3B), and CONTINUOUS (Fig. 3C) conditions. A significant main effect of group was also found for Purkinje cell density $\left(F_{(1,41)}=39.47, p<0.01\right)$. The AC animals had significantly reduced Purkinje cell densities in comparison to the MC animals in the EARLY and CONTINUOUS conditions but not in the DELAY condition (Student Neuman-Keuls, $p<$ 0.01 ) (Table 2). Synapse densities did not significantly differ between groups in any condition (Table 3).

\section{DISCUSSION}

Several experiments have now shown that motor skill acquisition is associated with increases in synapse number within motor regions of the brain and that this increase is not attributable to motor activity (Black et al., 1990; Federmeier et al., 1994; Kleim et al., 1994, 1996a). The results of this experiment show that both the motor skills and the associated increase in synapse number
A

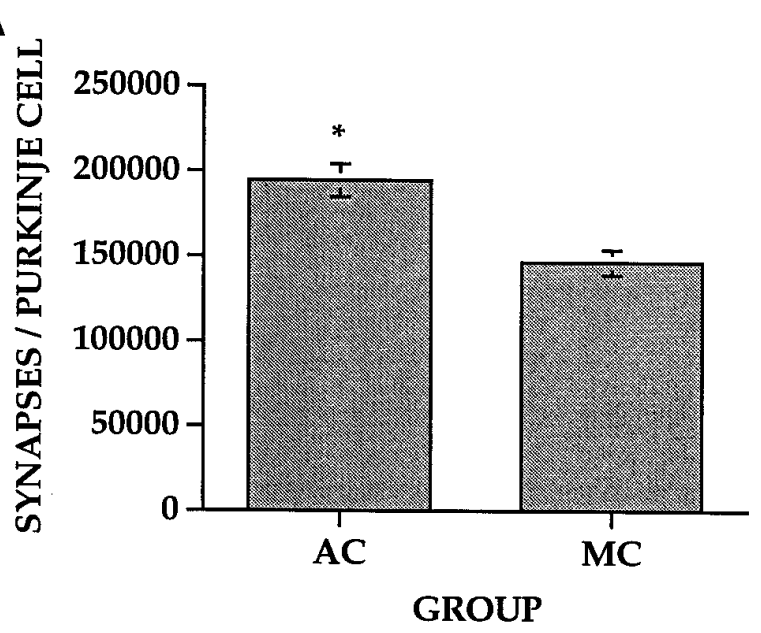

B

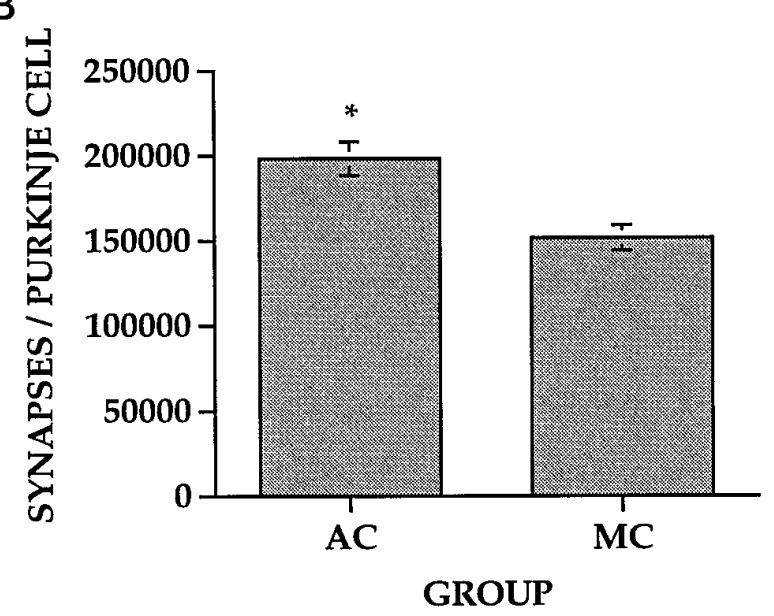

C

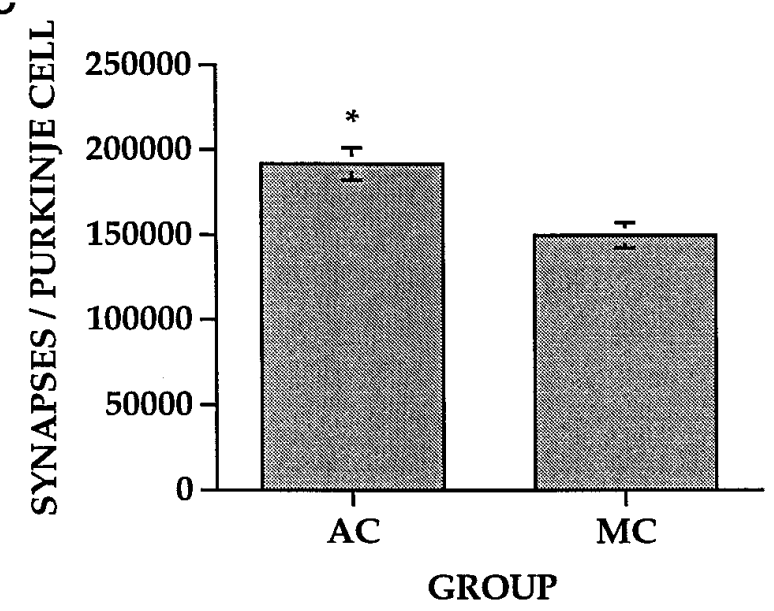

Figure 3. Number of synapses per Purkinje cell $( \pm$ SEM) within the PML. Multiple comparisons ( $*$ Student-Newman-Keuls, $p<0.05$ ) showed that the AC animals had significantly more synapses per Purkinje cell than the MC animals in the EARLY $(A), \operatorname{DELAY}(B)$, and CONTINUOUS $(C)$ conditions.

within the cerebellar cortex persist for at least $28 \mathrm{~d}$ after the cessation of training. These data are in agreement with previous findings showing that the increased number of varicosities per sensory neuron associated with sensitization of the gill withdrawal 


\begin{tabular}{|c|c|c|c|}
\hline Group & EARLY & DELAY & CONTINUOUS \\
\hline $\mathrm{AC}$ & $\begin{array}{c}* 2054 \pm(82) \\
(n=8)\end{array}$ & $\begin{aligned} 2122 & \pm(88) \\
(n & =8)\end{aligned}$ & $\begin{array}{c}* 1902 \pm(62) \\
(n=8)\end{array}$ \\
\hline $\mathrm{MC}$ & $\begin{array}{c}2449 \pm(118) \\
(n=7)\end{array}$ & $\begin{array}{c}2392 \pm(92) \\
(n=8)\end{array}$ & $\begin{array}{c}2535 \pm(106) \\
(n=8)\end{array}$ \\
\hline
\end{tabular}

Density of Purkinje cells $( \pm$ SEM) within the paramedian lobule. Multiple comparisons ( *Student-Newman-Keuls; $p<0.05$ ) showed that the AC animals had significantly lower Purkinje cell densities than the MC animals in the EARLY and CONTINUOUS conditions.

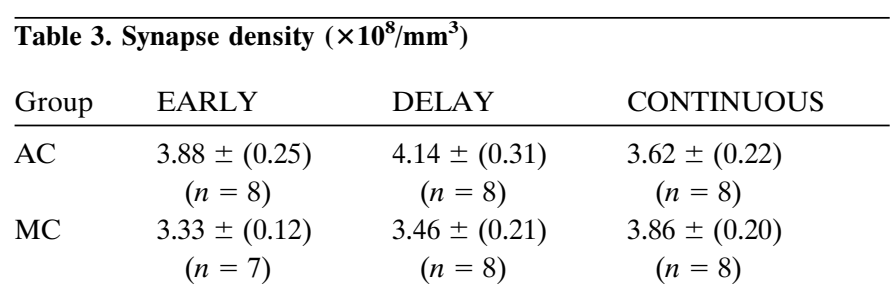

Density of synapses $( \pm$ SEM) within the molecular layer of the parmedian lobule. Multiple comparisons (Student-Newman-Keuls; $p<0.05$ ) showed no significant differences between the MC and $\mathrm{AC}$ groups in any condition.

reflex in Aplysia also persists for at least 3 weeks (Bailey and Chen, 1989).

The increased dendritic branching associated with postweaning exposure to complex housing also outlasts the experience (Camel et al., 1986). Recent work in our laboratory, however, has shown that the increase in number of synapses per neuron within the visual cortex of adult rats placed for 1 month in complex housing conditions decreases to statistical nonsignificance after a subsequent month in individual cages (Klintsova et al., 1995). The seemingly more persistent nature of the morphological consequences of motor skill training may arise from the fact that the skills develop gradually in relatively small increments. This progressive behavioral tuning may be represented in the brain as the gradual refinement of cerebellar circuitry involving increases in synapse number. Furthermore, the nature of the two tasks is somewhat different. Training on the motor learning task involves the goal-directed acquisition of specific behaviors related to the completion of a task that remains constant throughout the experience. Rearing in a complex environment is characterized by a more generalized experience involving the nonspecific exploration of a continuously changing environment. The specificity of the experience and the presence of behavioral demand associated with the motor learning task may account for the difference in the resilience of the anatomical changes observed in these two paradigms.

The primary site of plastic change within the cerebellar cortex after acrobatic training appears to be the parallel fiber to Purkinje cell synapse (Kleim et al., 1994; Anderson et al., 1996). This alteration seems to involve the formation of multiple synapses onto existing parallel fiber varicosities (Federmeier et al., 1994) and is reflected physiologically as enhanced Purkinje cell responsiveness to parallel fiber activation (Bendre et al., 1995). Recent work has also demonstrated an increase in the number of synapses per neuron within the motor cortex after motor learning and that this increase is dependent on the amount of training the animals receive (Kleim et al., 1996a). The persistence of the changes therefore may depend on the amount of training the animals receive before the delay period. It would be of interest to examine the permanence of both the motor skills and the increased synapse number after a shorter initial training period. It is also interesting to note the striking similarity in the number of synapses per Purkinje cell within each training condition. Both the AC and MC animals had comparable numbers of synapses per Purkinje cell across the three training schedules, and these values are similar to previously obtained estimates (Kleim et al., 1994). These data suggest that synapse-to-Purkinje cell ratio within the PML is quite consistent and shows a similarly consistent response to experience. In addition to the persistent change in synapse number, the present experiment also suggests that some of the anatomical consequences of motor skill learning may not persist. The decrease in Purkinje cell density in the AC EARLY and CONTINUOUS conditions indicates an increase in the volume of neuropil that has been shown previously to involve increased vasculature (Isaacs et al., 1992) and glial volume (Anderson et al., 1994). The AC animals in the DELAY condition, however, did not maintain the significantly decreased Purkinje cell density, which suggests that some anatomical correlates of the experience may not persist. Further examination may provide some insight into which anatomical changes are associated with the acquisition and continued performance of motor skill versus those that are associated with the maintenance of motor skill in the absence of continued performance.

\section{REFERENCES}

Anderson BJ, Li X, Alcantara AA, Isaacs KR, Black JE, Greenough WT (1994) Glial hypertrophy is associated with synaptogenesis following motor skill learning, but not with angiogenesis following exercise. Glia 11:73-80.

Anderson BJ, Alcantara AA, Greenough WT (1996) Motor skill learning: changes in synaptic organization of the rat cerebellar cortex. Neurobiol Learn Mem, in press.

Anker RL, Cragg BG (1974) Estimation of the number of synapses in a volume of nervous tissue from counts in thin sections by electron microscopy. J Neurocytol 3:725-735.

Bailey CH, Chen M (1983) Morphological basis of long-term habituation and sensitization in Aplysia. Science 220:91-93.

Bailey CH, Chen M (1989) Time course of structural changes at identified sensory neuron synapses during long-term sensitization in Aplysia. J Neurosci 9:1774-1780.

Bailey CH, Kandel ER (1993) Structural changes accompanying memory storage. Annu Rev Physiol 16:397-426.

Bendre AA, Swain RS, Wheeler BC, Greenough WT (1995) Augmentation of cerebellar responses to parallel fiber activation following skilled motor acquisition in rats. Soc Neurosci Abstr 21:444.

Berthier NE, Moore JW (1986) Cerebellar Purkinje cell activity related to the classically conditioned nictitating membrane response. Exp Brain Res 63:341-350.

Bhide PG, Bedi KS (1984) The effects of a lengthy period of environmental diversity on well-fed and previously undernourished rats. II. Synapse-to-neuron ratios. J Comp Neurol 227:305-310.

Black JE, Isaacs KR, Anderson BJ, Alcantara AA, Greenough WT (1990) Learning causes synaptogenesis whereas motor activity causes angiogenesis in cerebellar cortex of adult rats. Proc Natl Acad Sci USA 87:5568-5572.

Camel JE, Withers GS, Greenough WT (1986) Persistence of visual cortex dendritic alterations induced by postweaning exposure to a "superenriched" environment in rats. Behav Neurosci 100:810-813.

Chang FLF, Greenough WT (1982) Lateralized effects of monocular training on dendritic branching in adult split-brain rats. Brain Res 232:283-292.

Diamond MC, Krech D, Rosenzweig MR (1964) The effects of an enriched environment on the histology of the rat cerebral cortex. J Comp Neurol 123:111-120.

Federmeier K, Kleim JA, Anderson BJ, Greenough WT (1994) Formation of double synapses in the cerebellar cortex of the rat following motor learning. Soc Neurosci Abstr 20:1435. 
Forgays DG, Read JM (1962) Crucial periods for free environmental experience in the rat. J Comp Physiol Psychol 45:322-328.

Gilbert PFC, Thach WT (1977) Purkinje cell activity during motor learning. Brain Res 128:309-328.

Globus A, Rosenzweig MR, Bennett EL, Diamond MC (1973) Effects of differential experience on dendritic spine counts in rat cerebral cortex. J Comp Physiol Psychol 82:175-181.

Greenough WT, Bailey CH (1988) Anatomy of memory: convergence of results across a diversity of tests. Trends Neurosci 11:142-147.

Greenough WT, Juraska JM, Volkmar FR (1979) Maze training effects on dendritic branching in occipital cortex of adult rats. Behav Neural Biol 26:287-297.

Greenough WT, Larson JR, Withers GS (1985) Effects of unilateral and bilateral training in a reaching task on dendritic branching of neurons in the rat motor-sensory forelimb cortex. Behav Neural Biol 44:301-314.

Hore J, Vilis T (1984) A cerebellar-dependent efference copy mechanism for generating appropriate muscle responses to limb perturbations. In: Cerebellar functions (Bloedel JR, Dichgans J, Precht W, eds), pp 24-35. Berlin: Springer.

Isaacs KR, Anderson BJ, Alcantara AA, Black JE, Greenough WT (1992) Exercise and brain: angiogenesis in the adult rat cerebellum after vigorous physical activity and motor skill learning. J Cereb Blood Flow Metab 12:110-119.

Katz HB, Davies CA (1984) Effects of differential environments on the cerebral anatomy of rats as a function of previous and subsequent housing conditions. Exp Neurol 83:274-287.

Kleim JA, Napper RMA, Swain RA, Armstrong KE, Jones TA, Greenough WT (1994) Selective synaptic plasticity in the cerebellar cortex of the rat following complex motor learning. Soc Neurosci Abstr 20:1435.

Kleim JA, Lussnig E, Schwarz ER, Greenough WT (1996a) Synaptogenesis and FOS expression in the motor cortex of the adult rat after motor skill learning. J Neurosci 16:4529-4535.

Kleim JA, Pipitone MA, Kelly J, Drew J, Czerlanis CM, Greenough WT (1996b) An examination of lateral cerebellar nucleus morphology following complex motor learning in the rat. Soc Neurosci Abstr 22:439.
Klintsova AY, Bhattacharyya R, Greenough WT (1995) Persistence of synaptic plasticity under prolonged and reversible environmental conditions in adult rat visual cortex. Soc Neurosci Abstr 21:445.

Lavond DG, Logan CG, Sohn JH, Garner WDA, Konzawa SA (1990) Lesions of the cerebellar interpositus abolish both nictitating membrane and eyelid EMG conditioned responses. Brain Res 514:238-248.

Lincoln JS, McCormick DA, Thompson RF (1982) Ipsilateral cerebellar lesions prevent learning of the classically conditioned nictitating membrane/eyelid response. Brain Res 242:190-193.

Ojakangas CL, Ebner TJ (1992) Purkinje cell complex and simple spike changes during a voluntary arm movement learning task in the monkey. J Neurophysiol 68:2222-2236.

Pakkenberg B, Gundersen HJG (1988) Total number of neurons and glial cells in human brain nuclei estimated by the disector and the fractionator. J Microsc 150:1-20.

Rosenzweig MR, Krech D, Bennett EL, Diamond MC (1962) Effects of environmental complexity and training on brain chemistry and anatomy: a replication and extension. J Comp Physiol Psychol 55:429-437.

Sterio DC (1984) The unbiased estimation of number and size of arbitrary particles using the physical disector. J Microsc 134:127-136.

Thompson R, Huestis PW, Crinella FM, Yu J (1990) Brain mechanisms underlying motor skill learning in the rat. Am J Phys Med Rehabil 69:191-197.

Turner AM, Greenough WT (1983) Synapses per neuron and synaptic dimensions in occipital cortex of rats reared in complex, social or isolation housing. Acta Stereol [Suppl] 2:239-244.

Turner AM, Greenough WT (1985) Differential rearing effects on rat visual cortex synapses. I. Synaptic and neuronal density and synapses per neuron. Brain Res 329:195-203.

Volkmar FR, Greenough WT (1972) Rearing complexity affects branching of dendrites in the visual cortex of the rat. Science 176:1445-1447.

Withers GS, Greenough WT (1989) Reach training selectively alters dendritic branching in subpopulations of layer II-III pyramidals in rat motor-somatosensory forelimb cortex. Neuropsychologia 27:61-69. 